\section{Экспериментальные исследования состояния экосистем придорожной полосы}

\author{
В. К. Курьянов ${ }^{1}$ \\ А. В. Скрыпников \\ Воронежская государственная лесотехническая \\ академия
}

\begin{abstract}
АННОТАЦИЯ
В статье приводятся результаты экспериментальных исследований, проведенных в придорожной полосе автомагистрали «Дон», которые показали, что в процессе строительства и эксплуатации магистрали значительно изменились физико-химические и химические характеристики всех типов почв.
\end{abstract}

Ключевые слова: придорожная полоса, гумус, свинеи, кобальт, фоновое содержание, предельно допустимые концентрации (ПДК).

\section{SUMMARY}

The article deals with the results of experimental research made in the roadside of the motorway "Don", which showe that in the process of building and exploitation of the motorway physico-chemical and chemical characteristics of all types of soil have changed greatly.

Keywords: the roadside, humus, lead, cobalt, background content, concentration limit.

\section{СТРУКТУРА И ФИЗИКО-ХИМИЧЕСКИЕ ХАРАКТЕРИСТИКИ ПОЧВ}

Естественные почвы придорожной полосы автомагистрали «Дон» представлены светло-серыми, серыми и темно-серыми лесными почвами, оподзоленными, выщелоченными, типичными, обыкновенными и южными черноземами $[1,2]$.

По данным наблюдений, естественные почвы придорожной полосы на расстоянии 20-25 м от бровки насыпи сильно уплотнены, засорены строительным и бытовым мусором, в них практически отсутствуют генетические горизонты.

Особенностью преобразованных почв вдоль автомагистрали является их бесструктурность, низкая влагоемкость, изменение естественной окраски, отсутствие пористости.

\section{ДАННЫЕ ПО ФИЗИКО-ХИМИЧЕСКИМ ХАРАКТЕРИСТИКАМ ПОЧВ, ПОЛУЧЕННЫЕ В ЭКСПЕРИМЕНТАЛЬНЫХ ИССЛЕДОВАНИЯХ}

На основании данных исследований построены графические зависимости физико-химических характеристик почв от расстояния до бровки насыпи (рис. 1 4). Зависимости построены для данных, осредненных

\footnotetext{
${ }^{1}$ Авторы - соответственно профессор и ассистент
} кафедры транспорта леса и инженерной геодезии (C) В. К. Курьянов, А. В. Скрыпников, 2003 по типам почв, поскольку изменчивость внутри типов невелика (до 10-15\%) и сравнима с точностью анализа. Анализ данных графиков (рис. 1 - 4) показывает, что под влиянием автомагистрали произошло изменение природных физических и химических свойств почв придорожной полосы. Прежде всего, это касается реакции среды почвенного раствора (pH). Естественная $\mathrm{pH}$ серой лесной почвы - 4,0-4,5. По мере приближения к кромке дороги реакция среды становится более щелочной и на расстоянии 10 м от дороги достигает 5,8 .

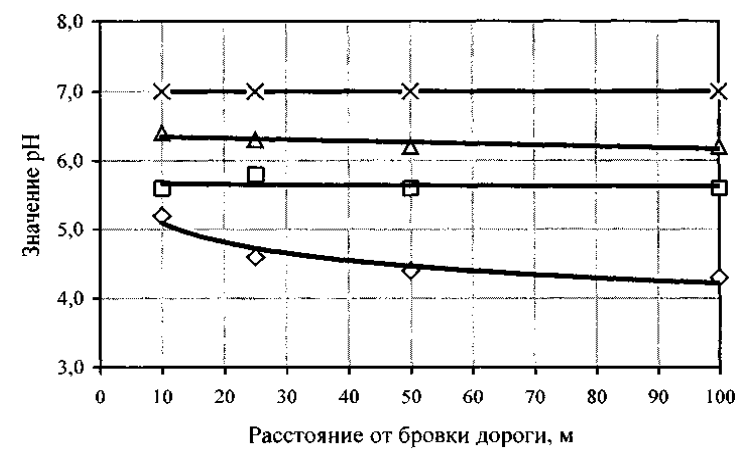

Рис. 1. Зависимость средней величины рН почвы придорожной полосы от расстояния до бровки

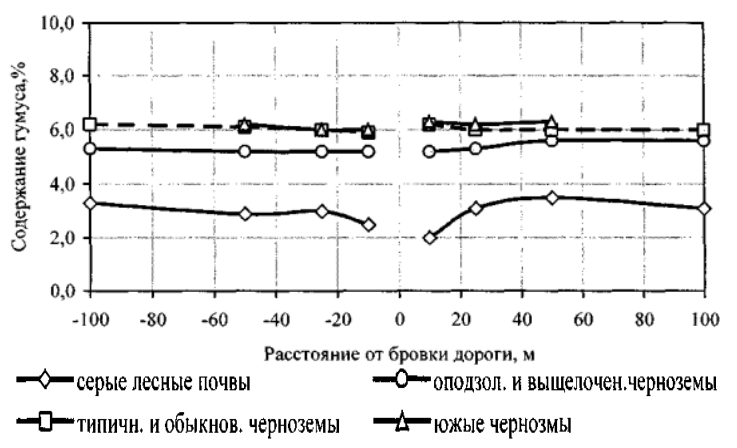

Рис. 2. Зависимость содержания гумуса в почве придорожной полосы от расстояния до бровки (отрицательные значения расстояния - слева от бровки, положительные значения - справа от бровки)
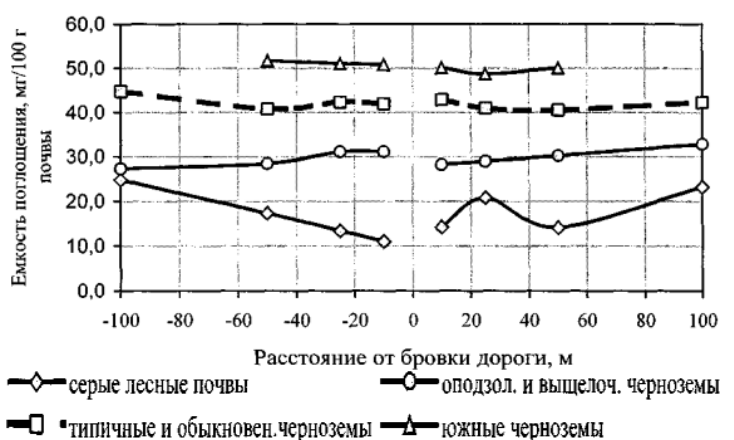

Рис. 3. Зависимость емкости поглощения почвы придорожной полосы от расстояния до бровки (отрицательные значения расстояния - слева от бровки, положительные значения - справа от бровки) 


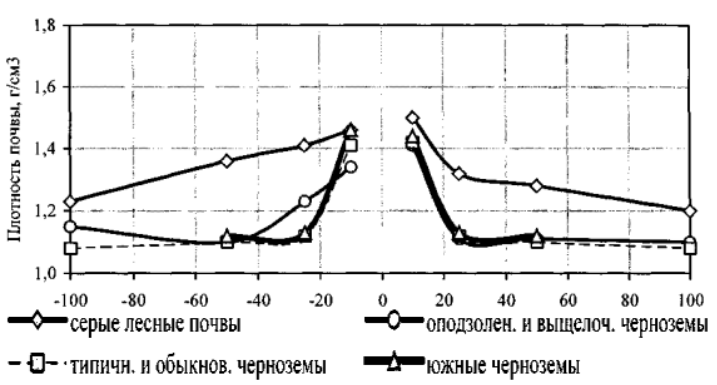

Рис. 4. Зависимость плотности почвы придорожной полосы от расстояния до бровки (отрицательные значения расстояния - слева от бровки, положительные значения - справа от бровки)

Подщелачивание серых лесных почв в придорожной полосе связано с поступлением в них выбросов, образующихся при работе двигателей транспортных средств, а также с попаданием в почву через поверхностный сток и дренажные воды хлоридов калия, кальция и натрия, которыми посыпают дорогу в зимний период. Накопление солей наиболее существенно на расстоянии первых 10 метров. При удалении от кромки дороги уже на 50 м реакция среды почвы становится кислой. Это объясняется, с одной стороны, генетическими свойствами почв - облегченным гранулометрическим составом, низкой буферностью, а с другой стороны - возможным выпадением осадков с повышенной кислотностью, формирующихся вследствие геохимической трансформации газообразных выбросов автотранспорта, содержащих соединения азота.

Черноземные почвы, как более высокобуферные, имеют реакцию среды, близкую к естественной, а именно: черноземы выщелоченные - слабокислую, черноземы типичные, обыкновенные и южные нейтральную.

Важным критерием химического преобразования почв является емкость поглощения и степень насыщенности основаниями. Почвы обследованной территории имеют различную емкость поглощения. Серые лесные почвы слабо насыщены основаниями, и емкость поглощения их низка. Особенно это касается 25 м полосы отчуждения автотрассы, где нарушено естественное сложение, поэтому и содержание катионов $\mathrm{Ca}^{2+}$ и $\mathrm{Mg}^{2+}$ в них очень небольшое. Емкость поглощения выщелоченного, типичного и обыкновенного черноземов составляет от 26 до 51 мг-экв/100 г почвы, что значительно выше нормы. Степень насыщенности почв основаниями колеблется от 83 до $100 \%$, что соответствует типичным значениям.

Физико-химические свойства почв являются показателями, характеризующими способность почв противостоять изменениям, происходящим при антропогенном загрязнении. Сравнение физико-химических свойств почв, расположенных на удалении 10 и 25 м от кромки дороги, с почвами 50-метрового и 100 метрового удаления показало, что около дороги они сильно деградированы, что связано с техногенным воздействием автотрассы. Все почвы, расположенные в 25-метровой зоне автотрассы, являются низкобуферными независимо от реакции среды. Их способность переводить в малоактивное состояние элементы-загрязнители очень слаба. Способность почв к самоочищению низкая.

Данные по содержанию гумуса обнаруживают сравнительно большие колебания в почвах всех типов и подтипов. Почвы, расположенные на расстоянии 10 25 м от кромки дороги, содержат крайне мало гумуса, что объясняется характером или полным отсутствием растительности, а также сильной деградацией почв. Кроме того, в жестких техногенных условиях, под действием автотрассы происходит интенсификация минерализационных процессов, диспергирование и вынос ранее накопленного гумуса, т.е. химическая эрозия почв, приводящая к механической эрозии и постепенному уничтожению естественного почвенного покрова. При отборе проб почв вдоль автомагистрали не обнаружено ни одного дождевого червя, что является ярким примером деградации почв, в первую очередь, снижения темпов гумусообразования. Снижение содержания гумуса может быть также следствием снятия гумусового горизонта при строительстве, реконструкции или ремонте трассы и перемешивании верхних слоев почвы с нижними слоями.

Важным показателем, демонстрирующим уровень деградации природных почв, является плотность сложения, характеризующая способность почвы накапливать значительные запасы необходимых для растений влаги и воздуха. Естественные и структурные почвы имеют невысокую величину плотности сложения. Плотность почвы сильно влияет на поглощение влаги, газообмен в почве, развитие корневых систем растений. Оптимальная плотность почвы для

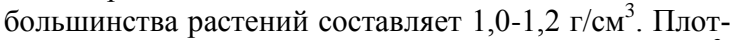
ность изученных почв колеблется от 1,62 до 1,1 г/см ${ }^{3}$. Сильно уплотнены серые лесные почвы на расстоянии 10 м и 25 м от кромки дороги. Черноземы, расположенные в непосредственной близости от трассы, также уплотнены, однако в меньшей степени, чем серые лесные почвы, что связано с более высоким содержанием гумуса. Общеизвестно, что органическое вещество почв способствует увеличению структурности и, следовательно, снижению плотности почвы.

Характеристика содержания тяжелых металлов в почвах придорожной полосы является одной из наиболее важных составляющих оценки техногенного воздействия на экосистемы. В процессе экспериментальных исследований изучалось валовое содержание следующих металлов: хрома, свинца, кадмия, никеля, кобальта, цинка и меди. На основании полученных данных построены графические зависимости содержания тяжелых металлов (мг/кг почвы) от расстояния до бровки насыпи (рис. 5 - 11). Для сопоставления с физико-химическими характеристиками почвы содержание тяжелых металлов усреднено по типам почв. 


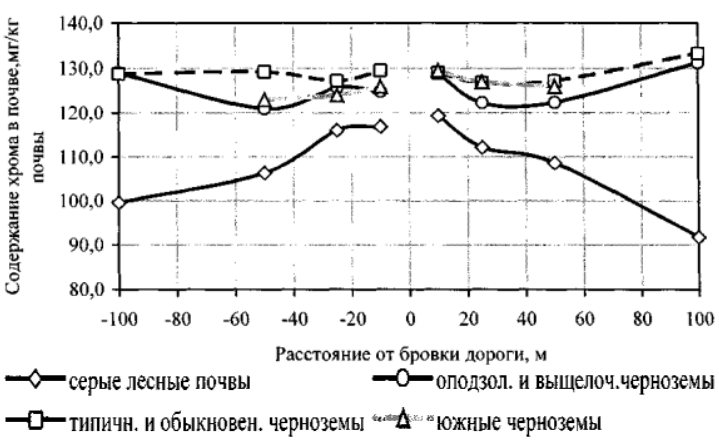

Рис. 5. Зависимость содержания хрома в почвах придорожной полосы от расстояния до бровки (отрицательные значения расстояния - слева от бровки, положительные значения - справа от бровки).

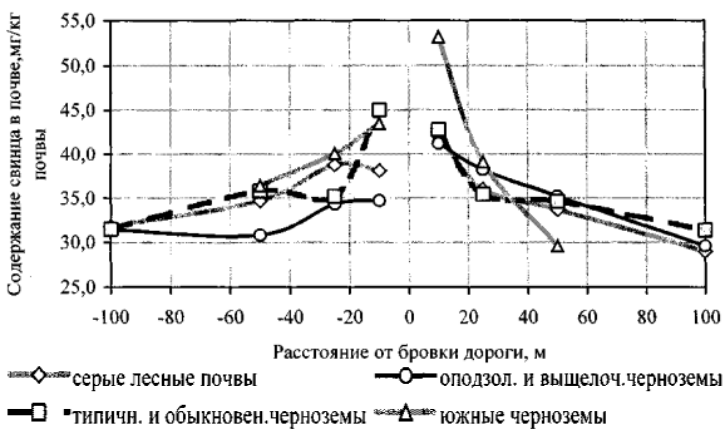

Рис. 6. Зависимость содержания свинца в почвах придорожной полосы от расстояния до бровки (отрицательные значения расстояния - слева от бровки, положительные значения - справа от бровки)

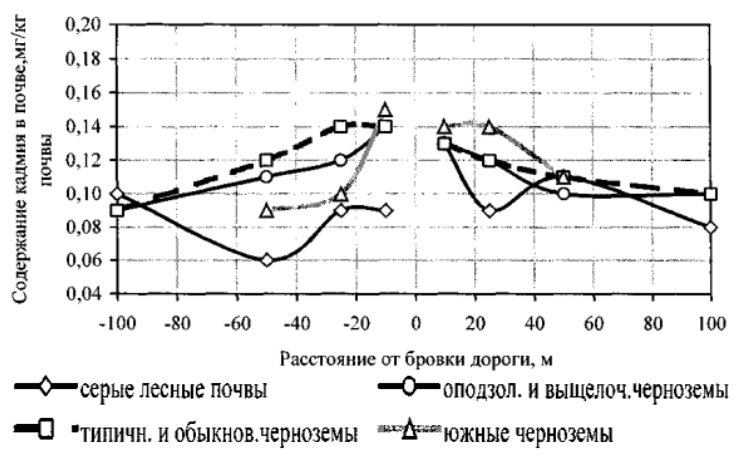

Рис. 7. Зависимость содержания кадмия в почвах придорожной полосы от расстояния до бровки (отрицательные значения расстояния - слева от бровки, положительные значения - справа от бровки)

Анализ табличных данных и графических зависимостей показывает, что для свинца, кадмия, цинка и меди четко прослеживается тенденция убывания содержания с увеличением расстояния от бровки насыпи, для хрома, никеля и кобальта эта тенденция менее заметна (только для отдельных типов почв). Осредненные по всем типам почв значения приводятся на рис. 12. Сходимость теоретических (сплошные ли- нии) и осредненных экспериментальных значений (отдельные точки) хорошая. Однако значения индивидуальных точек, вследствие неоднородности почвенных условий и влияния лесных полос, могут отклоняться от теоретических значений на $30-40 \%$.

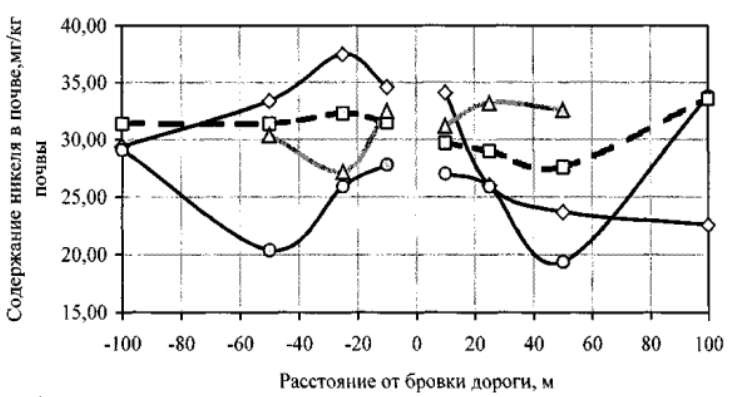

$$
\begin{aligned}
& \text { - серые лесные почвы } \\
& \text {-типичн. и обыкнов.черноземы южные черноземы }
\end{aligned}
$$

Рис. 8. Зависимость содержания никеля в почвах придорожной полосы от расстояния до бровки (отрицательные значения расстояния - слева от бровки, положительные значения - справа от бровки)

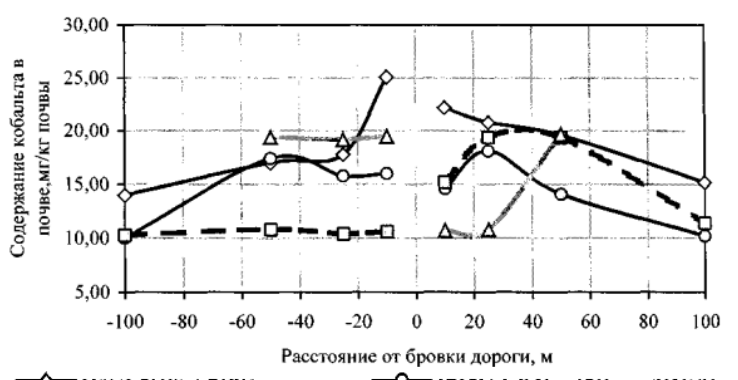

$\rightarrow$ - серые лесные почвы $\quad-0$-оподзол. и выщелоч.черноземы

- -типичн. и обыкнов.черноземы $-\Delta-$ южные черноземы

Рис. 9. Зависимость содержания кобальта в почвах придорожной полосы от расстояния до бровки (отрицательные значения расстояния - слева от бровки, положительные значения - справа от бровки)

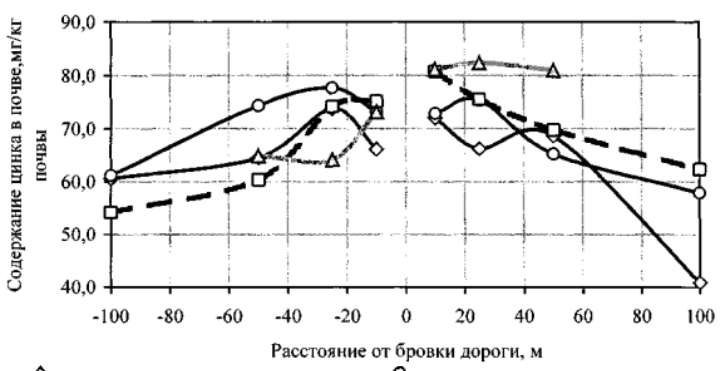

$\sim$ - серые лесные почвы

$\rightarrow$-типичн. и обыкнов.черноземы $\Delta$ - южные черноземы

Рис. 10. Зависимость содержания цинка в почвах придорожной полосы от расстояния до бровки (отрицательные значения расстояния - слева от бровки, положительные значения - справа от бровки)

Среднее содержание хрома в почвах оценивается в 55-65 мг/кг почвы. При техногенном поступлении хрома происходит его закрепление, перевод подвижных соединений в менее подвижные. Поглощение почвой хрома происходит за счет адсорбции глини- 
стыми минералами, анионной адсорбции гидроксилами железа и алюминия. Интенсивность адсорбции зависит от величины $\mathrm{pH}$. Хром обладает слабой растворимостью и низкой подвижностью, что позволяет предположить малую вероятность накопления его в трофических цепях.

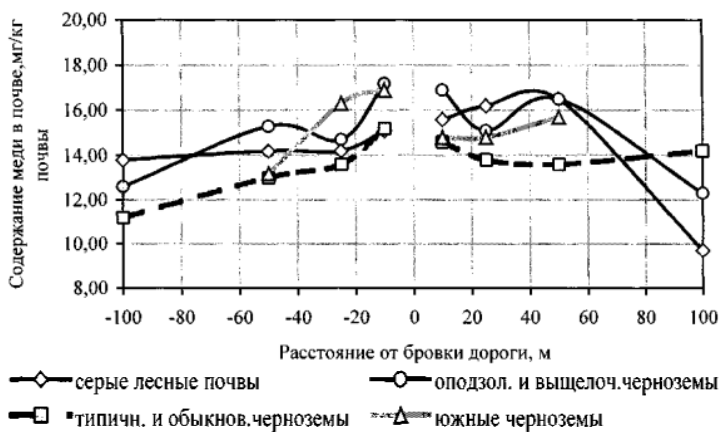

Рис. 11. Зависимость содержания меди в почвах придорожной полосы от расстояния до бровки (отрицательные значения расстояния - слева от бровки, положительные значения - справа от бровки)

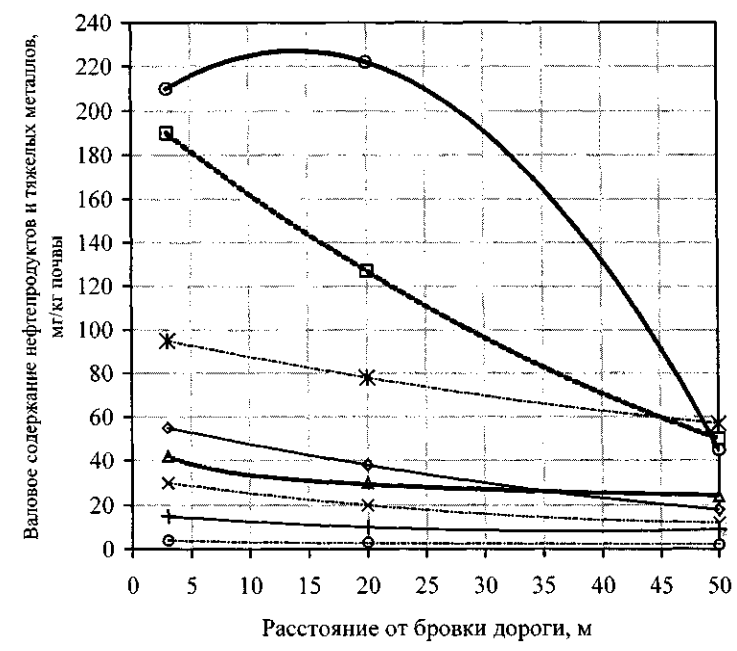

Рис. 12. Зависимость среднего содержания тяжелых металлов и нефтепродуктов в почвах придорожной полосы от расстояния до бровки $(\mathrm{O}-$ нефтепродукты, $-\mathrm{Cr}, ж-\mathrm{Zn}, \diamond-\mathrm{Pb}, \Delta-\mathrm{Ni}, \mathrm{x}-\mathrm{Co},+-\mathrm{Cu}, 0-\mathrm{Cd})$

Предельно допустимое содержание хрома в почве 90 мг/кг. Содержание хрома в почвах практически во всех взятых пробах, кроме 4 образцов (точки, удаленные от бровки насыпи на 50-100 м), превышает ПДК. Во всех образцах содержание хрома превышает фоновые значения. Причем, если для серых почв характерно уменьшение содержания хрома с удалением от бровки, то в черноземных почвах содержание хрома колеблется от 120 до 130 мг/кг почвы и практически не зависит от расстояния до бровки насыпи. Очевидно, что аэрозоли, содержащие хром, обладают высокой миграционной способностью.

Фоновые значения свинца составляют 16 мг/кг почвы в серых лесных почвах и 20 мг/кг почвы в черноземах, предельно допустимое значение - 32 мг/кг.
Свинец активно поглощается органическим веществом почвы, при содержании гумуса 2-4\% больше половины свинца почв прочно связано в составе лиганд. Растворимость соединений свинца достигается при рН ниже 3-5.

Содержание свинца в почвах придорожной полосы во всех образцах превышает фоновые значения. Значения, меньше ПДК, отмечаются, в основном, на расстояниях, превышающих 50 м. Учитывая высокую опасность соединений свинца для животных и человека, а также его накопление в трофических цепях, необходимо разрабатывать меры по предотвращению его поступления в придорожную полосу.

Фоновые значения кадмия в почвах составляют 0,200,24 мг/кг почвы. Предельно допустимая концентрация кадмия в почве -1 мг/кг почвы. На содержание кадмия оказывают влияние показатель $\mathrm{pH}$, процессы сорбции и окислительно-восстановительный потенциал почв. Наиболее эффективным процессом связывания кадмия является адсорбция его на глинах. Во всех отобранных образцах содержание кадмия близко к фоновым значениям, что указывает на отсутствие аккумуляции кадмия в почвах.

Фоновое содержание никеля колеблется от 35 мг/кг почвы в серых почвах и до 45 мг/кг в черноземах. ПДК никеля в почвах - 40 мг/кг почвы. Никель проявляет большое сродство к органическому веществу и концентрируется в нефти и нефтепродуктах, поэтому большое количество никеля выбрасывается при сжигании топлива. Соединения никеля очень мобильны и легко внедряются в трофические цепи.

В большинстве проб содержание никеля не превышает фоновых значений и ПДК. Однако для ряда точек характерно превышение ПДК никеля, что указывает на необходимость принятия мер по дезактивации прилегающих к дороге земельных участков.

Фоновое содержание кобальта в серых лесных почвах - 12 мг/кг почвы, черноземах - 15 мг/кг почвы. В большинстве образцов содержание кобальта либо близко, либо превышает фоновые значения. Прослеживается четкая закономерность уменьшения содержания кобальта с увеличением расстояния от бровки насыпи.

Фоновое содержание цинка в почвах - 68 мг/кг почвы. Основными процессами, определяющими содержание цинка в почвах, являются сорбция глинистыми минералами и гидроокисями железа и реакция среды [3]. Значительное превышение фоновых значений цинка обнаружено во всех пробах. Высокие значения обнаружены в почвах перед лесной полосой, что указывает на барьерный эффект лесных насаждений. Высокая подвижность соединений цинка по пищевым цепям указывает на достаточно высокую опасность загрязнения почв этим элементов в придорожной полосе автомагистрали «Дон».

Фоновое содержание меди в серых лесных почвах - 
12 мг/кг почвы, черноземах - 25 мг/кг почвы. Медь хорошо сорбируется минералами и органическими соединениями и является малоподвижным элементом $[4,5]$.

Превышение фоновых значений меди в 1,5 раза отмечается в серых лесных почвах. В целом содержание меди убывает с увеличением расстояния от бровки насыпи. Однако у лесных полос отмечается увеличение содержания меди, что указывает на барьерный эффект в аэрогенном распространении элемента.

Нефтепродукты являются одним из наиболее опасных загрязнителей, поскольку при попадании их в почву придорожной полосы происходят глубокие изменения химических, физических и микробиологических свойств, а иногда и перестройка всего почвенного профиля $[6,7]$.

В процессе экспериментальных исследований взяты пробы на содержание в почвах нефтепродуктов. На основании данных, полученных в результате химического анализа, предложены графические зависимости содержания нефтепродуктов (мг/кг почвы) от расстояния до бровки насыпи, при этом их содержание осреднено по всем почвам и сторонам дороги (рис. 12).

Анализ данных показывает, что содержание нефтепродуктов постоянно меняется и практически мало зависит от типа почвы. Наибольшие значения, как правило, наблюдаются на близких от бровки насыпи расстояниях. Однако, в ряде случаев, чрезвычайно высокие значения (1600 - 2000 мг/кг почвы) обнаружены на расстоянии 50 и 100 м (312-й и 363-й км). В серых лесных почвах, несмотря на отдельные очень высокие значения, содержание нефтепродуктов меньше, чем в черноземах, обладающих более тяжелым гранулометрическим составом. Это свидетельствует о большей миграции нефтепродуктов по профилю.

Фоновое содержание нефтепродуктов в почве 50 мг/кг почвы. Во всех взятых образцах оно превышено. Причем превышение составляет от 1,5 до 40 раз. Это указывает на повсеместную загрязненность почв нефтепродуктами и необходимость принятия мер по ликвидации данного загрязнения.

Экспериментальные исследования, проведенные в придорожной полосе автомагистрали «Дон», показали, что в процессе строительства и эксплуатации магистрали значительно изменились физикохимические и химические характеристики всех типов почв; для всех типов почв в полосе 25 м от бровки характерны повышенная плотность, бесструктурность, низкая влагоемкость, множество посторонних включений; валовое содержание большинства тяжелых металлов в почвах уменьшается с увеличением расстояния от бровки насыпи; наиболее опасным в придорожной полосе является загрязнение почв хромом и свинцом; повсеместно наблюдается очень высокое загрязнение почв придорожной полосы нефтепродуктами (в 1,5 - 40 раз больше ПДК).

\section{СПИСОК ЛИТЕРАТУРЫ}

1. Курьянов В. К., Скрыпников А. В. Эксплуатационные документы систем моделирования процессов функционирования дороги в рабочем проекте первой очереди САПР-АД // Рациональное использование лесных ресурсов: Материалы международной научно-практической конференции, посвященной 100-летию со дня рождения В. Е. Печенкина / Под общ. ред. Ю. А. Ширина. Йошкар-Ола: Изд-во МарГТУ, 2001. 205 с.

2. Скрыпников А. В. Методы оценки техникоэкономических, энергетических, экологических показателей функционирования дороги / Воронеж. гос. лесотехн. акад. Деп. в ВИНИТИ 12.03.01. № 616-В2001. 14 c.

3. Курьянов В. К., Афоничев Д. Н., Бурмистрова О. Н., Скрыпников А. В. Повышение транспортно-эксплуатационных качеств автомобильных дорог лесопромышленного комплекса: Монография / Воронеж. гос. лесотехн. акад., Ухтинск. гос. техн. ун-т. Воронеж: Изд-во Воронеж. гос. ун-та, 2002.

4. Кроха В. А., Скрыпников А. В. Влияние температуры деформации на деформационное поведение меди при сжатии // Математическое моделирование, компьютерная оптимизация технологий, параметров оборудования и систем управления лесного комплекса: Сб. научных трудов ВГЛТА. Воронеж, 1998.

5. Курьянов В. К. Скрыпников А. В. Современные критерии оценки транспортно-эксплуатационных качеств автомобильных дорог / Воронеж. гос. лесотехн. акад. М., 2000. Деп. в ВИНИТИ 15.03.00, № 648-B00.

6. Курьянов В. К., Скрыпников А. В. Современные этапы развития автомобильного проектирования дорог (САПР-АД) // Математическое моделирование, компьютерная оптимизация технологий, параметров оборудования и систем управления лесного комплекса: Межвуз. сб. науч. тр. / Под ред. проф. В. С. Петровского; ВГЛТА. Воронеж, 2000. 259 c.

7. Скрыпников А. В., Бурмистрова О. Н. Экологические показатели функционирования автомобильных дорог в системах автоматизированного проектирования // Лес и молодежь. ВГЛТА 2000 г.: Сб. науч. тр. юбилейной конференции молодых ученых, посвященной 70-летию образования ВГЛТА / Под ред. акад. РАЕН Л. Т. Свиридова; ВГЛТА. Воронеж, 2000. Т. 1. 186 с. 